\title{
Prevalence and Determinants of Modern Contraceptive Methods Use among Women of Reproductive Age (15 - 49 Years) in Rural Setting: A Case of Kishapu District, Shinyanga Region
}

\author{
Veronica Martin1, Sia E. Msuya, 1,2,3, Ntuli Kapologwe4, Damian J. Damian²,3, Beatrice John1, \\ Michael J. Mahande ${ }^{*}$ \\ ${ }^{1}$ Department of Epidemiology and Biostatistics, Institute of Public Health, Kilimanjaro Christian Medical University College, \\ Moshi, Tanzania \\ ${ }^{2}$ Kilimanjaro Christian Medical Centre, Moshi, Tanzania \\ ${ }^{3}$ Community Health Department, Kilimanjaro Christian Medical University College, Moshi, Tanzania \\ ${ }^{4}$ Shinyanga Regional Medical Office, Shinyanga, Tanzania \\ Email: veronica martin333@gmail.com, siamsuya@hotmail.com,nkapologwe2002@gmail.com,d_jeremy5@yahoo.com, \\ beatrice_john@yahoo.com,jmmahande@gmail.com
}

\begin{abstract}
How to cite this paper: Martin, V., Msuya, S.E., Kapologwe, N., Damian, D.J., John, B. and Mahande, M.J. (2019) Prevalence and Determinants of Modern Contraceptive Methods Use among Women of Reproductive Age (15 - 49 Years) in Rural Setting: A Case of Kishapu District, Shinyanga Region. Advances in Sexual Medicine, 9, 53-66.
\end{abstract}

https://doi.org/10.4236/asm.2019.94005

Received: December 17, 2017

Accepted: September 6, 2019

Published: September 9, 2019

Copyright () 2019 by author(s) and Scientific Research Publishing Inc. This work is licensed under the Creative Commons Attribution International License (CC BY 4.0).

http://creativecommons.org/licenses/by/4.0/

\begin{abstract}
Background: Modern contraceptive use among women of reproductive age (15 - 49 years) is a public health priority in Tanzania. The national prevalence remains unacceptably low as $32 \%$. Shinyanga region is one among the regions with lowest contraceptive prevalence rate $(21 \%)$ and high unmet need for family planning (23\%). Understanding factors contributing to its use may help to improve maternal and child health. This study aimed to assess the prevalence and determinants of modern contraceptive use among women of reproductive age. Methods: A community-based cross-sectional study was conducted in Kishapu district of Shinyanga region: A total of 602 women aged 15 - 49 years were interviewed using a standardized questionnaire. Data were analysed using SPSS version 20.0. Odds ratios with 95\% confidence intervals for factors associated with use of modern contraceptives were estimated in multivariable logistic regression models. Results: The prevalence of modern contraceptive use was 42.7\%. Being employed (OR 2.42, 95\% CI: 1.13 - 5.18), formal educational level (OR 2.45, 95\% CI: 1.38 - 4.35), couples communication (OR 2.44, 95\% CI: 1.74 - 3.42) and availability of modern contraceptives (OR 1.94, 95\% CI: 1.17 - 3.20) were significantly associated with current use of modern contraceptives. Husband disapproval was frequently reported as barrier for modern contraceptives in the study area. Con-
\end{abstract}


clusions: Numerous factors were associated with use of modern contraceptives. Husband disapproval was frequently reported as barrier for contraceptive use. Strategies to promote the importance of modern contraceptives use in the study area are warranted. District health office and concerned stakeholders should encourage male involvement for family planning.

\section{Keywords}

Family Planning, Modern Contraceptive Use, Prevalence, Determinants

\section{Introduction}

Family planning plays a crucial role in advancing quality health improvements and it helps to accelerate the achievement of Sustainable Development Goals 3 [1]. Modern contraceptive methods account for the majority of current global contraceptive practices compared to traditional methods, where about 9 people out of 10 users of family planning use modern contraceptives [1] [2]. In 2012, the global modern contraceptive prevalence was $57 \%$ [2]. Contraceptive prevalence levels will need to reach at least $66 \%$ - 75\% in developed regions and $67 \%$ in developing countries in order to attain the targeted decline in fertility by the year 2025 [2].

Family planning has numerous advantages including: ensuring couples achieve desired family, reducing infant/perinatal and maternal mortality, preterm birth, low birth weight and abortion [3]. It also reduces the risk of HIV transmission, STIs acquisition and prevents unintended pregnancies. Furthermore, family planning reduces pregnancy-related health risks in women as it gives enough time to a mother to recover from the previous pregnancy [3] [4].

Globally, the prevalence of modern contraceptive use has slightly increased from $54 \%$ in 1990 to $57 \%$ in 2012 , but this increase has not been reflected in developing countries where the use of modern contraceptive among women of reproductive age is about 43\% [2] [5]. There is also a wide gap of utilization of modern contraceptives between higher and lower income countries $(52 \%$ vs. $35 \%$, respectively) [5].

Majority of Sub-Sahara Africa countries have modern contraceptive use rates below the average for developing countries, with only Zimbabwe which has reported modern contraceptive prevalence rate of $66 \%$ among married women [6]. In Tanzania the prevalence of modern contraceptive use among women of reproductive age ( 15 - 49 years) is $32 \%$ [7]. The use of any contraceptives also varies between married and unmarried women ( $38 \%$ vs. $54 \%$, respectively), and among sexually active unmarried women is $46 \%$ [7]. The prevalence of modern contraceptive use also varies across regions and districts in Tanzania ranging from $13 \%$ in Geita region to $52 \%$ in Lindi region; with unmet need for family planning estimated to range from $10 \%-35 \%$ [7]. The modern contraceptive prevalence rate in Shinyanga region was reported to be $21 \%$, while the unmet 
need was $23 \%$ [7].

Previous studies have reported numerous factors associated with use of modern contraceptives including socio-demographic, socio-cultural, socio-economic, obstetric, social marketing and media exposure [5] [6] [7] [8]. Despite the lower prevalence of modern contraceptive use in the region, there is also no study which has investigated factors associated with modern contraceptive use among women of reproductive age in this region. This study aimed to assess the prevalence and determinants of modern contraceptive use among women of reproductive age (15 - 49 years) in Kishapu district, Shinyanga region.

\section{Methods}

\subsection{Study Design and Setting}

This was a community based analytical cross-sectional study which was conducted from $1^{\text {st }}$ of May to $30^{\text {th }}$ May, 2015 in Kishapu district. Kishapu is one of the five districts in Shinyanga region located in the North central Tanzania. Kishapu district has a total population of 272,990 (135,269 vs. 137,721 , for male and female respectively) [9]. The district administration is divided into 3 divisions, which are further divided into 25 wards with 125 villages. The main economic activities in the study area are agriculture and livestock keeping.

\subsection{Study Population and Sampling Techniques}

Study population included women of reproductive age from six selected villages in the district. The multistage sampling technique was employed to select the 602 women of reproductive age. It involved three stages; $1^{\text {st }}$ stage involved selection of 3 wards out of 3 divisions. In the $2^{\text {nd }}$ stage, the selected wards were stratified into rural and urban ( 2 from rural and 1 from urban areas, respectively) were randomly selected. The $3^{\text {rd }}$ stage involved selection of villages from the selected wards, whereby 6 villages were selected (2 villages from each of the selected wards). Finally, the households where the women live selected. We used household rosters which were prepared by the national census as a sampling frame where all household members from each village were registered. By using the household roster we were able to select the women who met the preset criteria. The final sample units were obtained by randomly selecting individuals from the selected households.

\subsection{Study Variables}

The dependent variable was modern contraceptive use and independent variables were socio-demographic characteristics (age, religion, husband approval, spouse communication, marital status, education level, distance to the health centre, occupation, access to modern contraceptives/family planning services), reproductive history (number of living children, number of live births, parity, desire for more children). 


\subsection{Data Collection Tools and Procedures}

A questionnaire with both open ended and closed ended questions was used to obtain relevant information from the study participants. The English version of the questionnaire was translated into Kiswahili. Prior to the data collection, the questionnaire was pretested to 40 women of reproductive age (15 - 49 years) in different village from the study area to assess the clarity, appropriateness and comprehensiveness of the questions and time spent to conduct an interview for each participant.

The invitation to participate in the study was done in collaboration with village administration in the respective study villages. Ten research assistant were recruited from the university and oriented about the objective of the study, ethical issues, and meaning of questions and how to conduct interviews.

\subsection{Statistical Analysis}

Data analysis was performed using Statistical package for social sciences (SPSS) version 20.0. Descriptive statistics were used to summarize mean and standard deviation for continuous variables and proportion, for categorical variables. Odds ratios (ORs) with 95\% confidence intervals (CIs) for determinants of modern contraceptives use were estimated in logistic regression models. A $\mathrm{P}$-value of less than $<0.05$ was considered statistically significant.

\section{Results}

\subsection{Socio-Demographic Characteristics of the Participants}

A total of 602 women of reproductive age participated in this study. This corresponds to the response rate of $100 \%$. The mean age of the respondents was 28.68 (SD 8.03) years. Majority (78.1\%) had primary level of education and (78.7\%) were married. Nearly eighty per cent $(78.9 \%)$ of the participants were Christian and others were Muslims (8.5\%) and traditional (12.6\%). Regarding partners' characteristics about half (49.4\%) of partners aged between $30-42$ years with majority $(72.1 \%)$ reported to have primary education (Table 1 ).

\subsection{Awareness, Access and Availability of Modern Contraceptive Methods}

Most (94.9\%), of the participants reported to have heard about/be aware of family planning methods. Majority (88.4\%) reported that contraceptive methods were available for free and were easily accessed. Majority (87.8\%) of the respondents got information on family planning from the health facilities (Table 2).

\subsection{Reproductive History Characteristics of the Participants}

Forty per cent of the respondents had delivered live births 3 - 5 times, while $43 \%$ of the participants had had less than 2 live births. Majority (71.3\%) of the participants reported to have desire for more children in the future (Table 3 ). 
Table 1. Socio-demographic characteristics among the participants $(\mathrm{N}=602)$.

\begin{tabular}{|c|c|c|}
\hline Characteristics & $\mathrm{n}$ & $\%$ \\
\hline \multicolumn{3}{|l|}{ Age of the participant } \\
\hline $15-21$ & 115 & 19.1 \\
\hline $22-28$ & 218 & 36.2 \\
\hline $29-35$ & 136 & 22.6 \\
\hline $36-42$ & 95 & 15.8 \\
\hline $43-49$ & 38 & 6.3 \\
\hline \multicolumn{3}{|c|}{ Educational status of women } \\
\hline No formal education & 68 & 11.3 \\
\hline Primary education & 470 & 78.1 \\
\hline Secondary education & 63 & 10.5 \\
\hline Higher education & 1 & 0.2 \\
\hline \multicolumn{3}{|l|}{ Occupation } \\
\hline Employed & 30 & 95 \\
\hline Unemployed & 572 & 5 \\
\hline \multicolumn{3}{|l|}{ Marital status } \\
\hline Married & 474 & 78.7 \\
\hline Unmarried & 128 & 21.3 \\
\hline \multicolumn{3}{|l|}{ Polygamous relationship } \\
\hline Yes & 136 & 22.6 \\
\hline No & 466 & 77.4 \\
\hline \multicolumn{3}{|l|}{ Religion } \\
\hline Christian & 475 & 78.9 \\
\hline Muslim & 51 & 8.5 \\
\hline Traditional & 76 & 12.6 \\
\hline \multicolumn{3}{|l|}{ Partner's age $(n=462)$} \\
\hline $17-29$ & 151 & 32.7 \\
\hline $30-42$ & 228 & 49.4 \\
\hline $43-55$ & 73 & 15.8 \\
\hline $56-68$ & 8 & 1.7 \\
\hline $69-81$ & 2 & 0.4 \\
\hline \multicolumn{3}{|c|}{ Partner's educational level } \\
\hline No formal education & 124 & 20.6 \\
\hline Primary education & 434 & 72.1 \\
\hline Secondary education & 39 & 6.5 \\
\hline Higher education & 5 & 0.8 \\
\hline
\end{tabular}

${ }^{\star} 140$ missing on partners' age because women did not know about their partner's age and others had no regular partner. 
Table 2. Awareness, access and availability of modern contraceptive methods $(\mathrm{N}=602)$.

\begin{tabular}{|c|c|c|}
\hline Characteristics & $\mathbf{n}$ & $\%$ \\
\hline \multicolumn{3}{|l|}{ Ever heard of family planning } \\
\hline Yes & 571 & 94.9 \\
\hline No & 31 & 5.1 \\
\hline \multicolumn{3}{|c|}{ Source of information for family planning } \\
\hline Health facilities & 529 & 87.8 \\
\hline Health care workers & 176 & 29.2 \\
\hline Friends/peers & 191 & 31.7 \\
\hline Family members & 34 & 5.6 \\
\hline Mass medium & 202 & 33.6 \\
\hline Community health workers & 12 & 2 \\
\hline \multicolumn{3}{|l|}{ Access to family planning } \\
\hline Easy & 533 & 88.5 \\
\hline Difficult & 69 & 11.5 \\
\hline \multicolumn{3}{|l|}{ Availability of family planning } \\
\hline Free of charge & 532 & 88.4 \\
\hline Paying & 70 & 11.6 \\
\hline \multicolumn{3}{|l|}{ Source of contraceptive methods* } \\
\hline Health facilities & 216 & 35.9 \\
\hline Pharmacies & 14 & 2.3 \\
\hline Cold drug shops & 53 & 8.8 \\
\hline From friends & 3 & 0.5 \\
\hline
\end{tabular}

${ }^{*}$ A respondent could name more than one source of information, thus the above do not add to total study group of 602 .

\subsection{Prevalence of Modern Contraceptive Use}

Over sixty five per cent $(68.3 \%)$ of the participants reported to have ever used any type of the contraceptive method, while 408 (67.8\%) of the participants reported to have ever used modern methods of contraception and only 257 (42.7\%) were currently using modern contraceptive methods (Table 4).

\subsection{Types of Modern Contraceptive Preferred among Users}

The most preferred methods among women who were currently using modern contraceptives (257) were injectable 89 (34.6\%) followed by male condoms 67 (26\%), implants 55 (21.4\%) and hormonal pills 33 (12.7\%) (Figure 1).

\subsection{Determinants for Modern Contraceptive Use}

The results from multiple logistic models for factors associated with modern contraceptive use are shown in Table 5. Being employed (OR 2.42, 95\% 
Table 3. Reproductive history characteristics of the study participants $(\mathrm{N}=602)$.

\begin{tabular}{|c|c|c|}
\hline Characteristics & $\mathbf{n}$ & $\%$ \\
\hline \multicolumn{3}{|l|}{ Having children } \\
\hline Yes & 549 & 91.2 \\
\hline No & 53 & 8.8 \\
\hline \multicolumn{3}{|l|}{ Parity } \\
\hline $0-2$ & 226 & 37.5 \\
\hline $3-5$ & 249 & 41.4 \\
\hline $6+$ & 127 & 21.1 \\
\hline \multicolumn{3}{|c|}{ Number of live birth } \\
\hline $0-2$ & 259 & 43 \\
\hline $3-5$ & 247 & 41 \\
\hline $6+$ & 96 & 15.9 \\
\hline \multicolumn{3}{|c|}{ Number of live children } \\
\hline $0-2$ & 261 & 43.4 \\
\hline $3-5$ & 254 & 42.2 \\
\hline $6+$ & 87 & 14.5 \\
\hline \multicolumn{3}{|c|}{ Desire for more children } \\
\hline Yes & 429 & 71.3 \\
\hline No & 173 & 28.7 \\
\hline
\end{tabular}

Table 4. Prevalence of modern contraceptive use among women of reproductive age in rural area Kishapu $(\mathrm{N}=602)$.

\begin{tabular}{ccc}
\hline Characteristics & n & \% \\
\hline Ever use any method of family planning & & \\
\hline Yes & 411 & 68.3 \\
No & 191 & 31.7 \\
\hline Ever use modern methods & & \\
\hline Yes & 408 & 67.8 \\
No & 194 & 32.2 \\
\hline Currently using modern methods & & \\
\hline Yes & 257 & 42.7 \\
No & 345 & 57.3 \\
\hline
\end{tabular}

CI: 1.13 - 5.18), age of the participants ranging between 25 - 49 years (OR 1.42, 95\% CI: 1.02 - 1.99), educational level of the participants (OR 2.45, 95\% CI: 1.38 - 4.35), parity (OR 1.53, 95\% CI: 1.09 - 2.15), number of live children (OR 1.45, 95\% CI: $1.05-2.02$ ) and availability of modern contraceptive methods for free (OR 1.94, 95\% CI: 1.17 - 3.20) were significantly associated with increased odds 


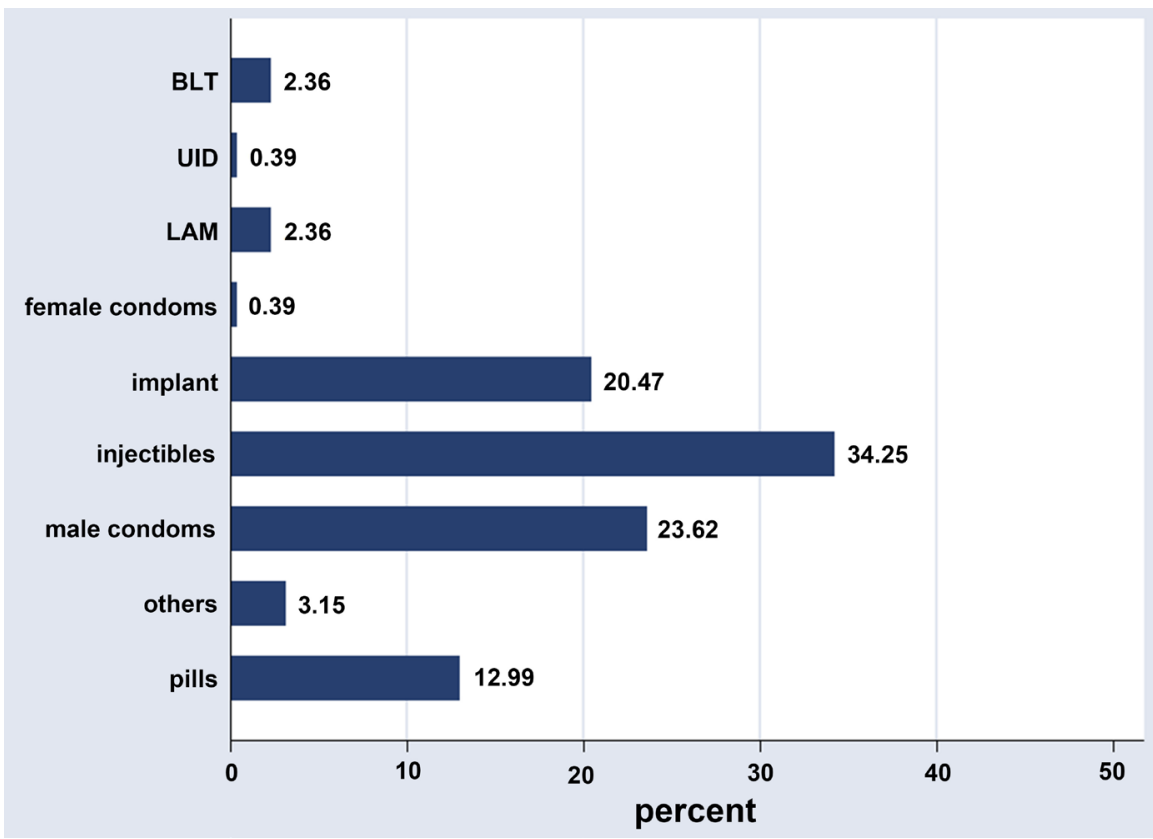

Figure 1. Types of modern contraceptive methods preferred among currently users in Kishapu district, Shinyanga $(\mathrm{n}=257)$.

of current use of modern contraceptive methods. On the other hand, polygamous relationship (marriage) and women or couples' desire to have more children were associated with lower odds of using of modern contraceptive methods as compared to their counterparts.

\subsection{Barriers for Modern Contraceptive Use}

Participants were asked about barriers for using modern contraceptives. The barriers mentioned were husband disapproval 209 (34.7\%), partners' ignorance 19 (3.1\%), fear of side effects $16(2.7 \%)$ and poor communication $14(2.3 \%)$ (Table 6).

\section{Discussion}

In this study we found that, the prevalence of modern contraceptive use was $42.7 \%$ and the most frequently preferred modern methods among users were injectable/Depo-Provera (34.6\%) and male condoms (26\%). The study also found that that, Age of the participants, spousal communication, education level, parity, number of live children and occupational status of the participant were associated with modern contraceptive methods use. However, the most common reported barrier for using modern contraceptive methods was husband disapproval which contributed for $34.7 \%$ of all barriers.

In the present study, the prevalence of modern contraceptive use was $42.7 \%$. This is higher compared with the regional and national prevalence of $21 \%$ vs $32 \%$ respectively [7]. The observed prevalence is also higher compared to $9.4 \%$ which was reported in Nigeria [10]. However, the prevalence of modern 
Table 5. Multiple logistic models for factors associated with modern contraceptive use (N $=345)$.

\begin{tabular}{|c|c|c|c|c|}
\hline \multirow[b]{2}{*}{ Characteristics } & \multicolumn{4}{|c|}{ Current use of modern methods } \\
\hline & No & Yes n (\%) & AOR & $95 \%$ CI \\
\hline \multicolumn{5}{|l|}{ Age of respondents } \\
\hline $15-24$ & 141 & $84(37.3)$ & & 1.0 \\
\hline $25-49$ & 204 & $173(45.9)$ & 1.42 & $1.02-1.99$ \\
\hline \multicolumn{5}{|l|}{ Occupation } \\
\hline Employed & 11 & $19(63.3)$ & 2.42 & $1.13-5.18$ \\
\hline Unemployed & 334 & $238(41.6)$ & & 1.0 \\
\hline \multicolumn{5}{|l|}{ Educational status } \\
\hline No formal education & 51 & $17(25)$ & & 1.0 \\
\hline with formal education & 294 & $240(44.9)$ & 2.45 & 1.384 .35 \\
\hline \multicolumn{5}{|l|}{ Marital status } \\
\hline Married & 262 & $212(44.7)$ & 0.67 & $0.45-1.01$ \\
\hline Unmarried & 83 & $45(35.2)$ & & 1.0 \\
\hline \multicolumn{5}{|l|}{ Polygamous relationship } \\
\hline Yes & 78 & $58(42.6)$ & 0.99 & $0.68-1.47$ \\
\hline No & 267 & $199(42.7)$ & & 1.0 \\
\hline \multicolumn{5}{|l|}{ Parity } \\
\hline$\leq 2$ & 144 & $82(36.3)$ & & 1.0 \\
\hline$\geq 3$ & 201 & $175(46.5)$ & 1.53 & $1.09-2.15$ \\
\hline \multicolumn{5}{|l|}{ Number of live children } \\
\hline$\leq 2$ & 163 & $98(37.5)$ & & 1.0 \\
\hline$\geq 3$ & 182 & $159(46.6)$ & 1.45 & $1.05-2.02$ \\
\hline \multicolumn{5}{|l|}{ Desire for more children } \\
\hline No & 99 & $74(42.8)$ & 0.99 & 1.0 \\
\hline Yes & 246 & $183(42.7)$ & & $0.69-1.42$ \\
\hline \multicolumn{5}{|l|}{ Couples communication } \\
\hline No & 181 & $80(30.7)$ & & 1.0 \\
\hline Yes & 164 & $177(51.9)$ & 2.44 & $1.74-3.42$ \\
\hline \multicolumn{5}{|c|}{ Availability of methods (FP) } \\
\hline Free of charge & 315 & $217(40.8)$ & 1.94 & $1.17-3.20$ \\
\hline Paying & 30 & $40(57.1)$ & & 1.0 \\
\hline
\end{tabular}

contraceptive use in our study falls within a range of $14 \%-45 \%$ reported by previous studies in sub-Sahara Africa [5]. However this prevalence is slightly lower to the study done in Ethiopia that reported the prevalence of modern contraceptive methods was $46.9 \%$ [8]. Also this prevalence is lower compared with the global prevalence of modern contraceptive use of $57 \%$ which was reported in 2012 [2]. The difference in prevalence of modern contraceptive use between our study and the previous studies may be explained by easy access of the methods 
Table 6. Barriers for use of modern contraceptive use $(\mathrm{N}=602)$.

\begin{tabular}{ccc}
\hline Characteristics & $\mathbf{n}$ & $\%$ \\
\hline Husband disapproval & 209 & 34.7 \\
Ignorance of partners & 19 & 3.1 \\
Lack of awareness & 7 & 1.2 \\
Cultural practices & 2 & 0.3 \\
Fear of side effects & 16 & 2.7 \\
Desire for more children & 8 & 1.3 \\
Poor spousal communication & 14 & 2.3 \\
Religious factors & 1 & 0.2 \\
Long distance to the health facility & 6 & 1 \\
\hline
\end{tabular}

*320 missing as they reported that were no barriers and others did not know.

of modern contraceptive and most of the methods are available for free in the present study. It may also be due to increased number of sources that provide family planning services and increase in advertisement through different mass media especially radio.

In this study the common preferred modern methods of contraception among users were injectable (34.6\%), male condoms (26\%), implants (21.4\%) and hormonal pills (12.7\%). This finding is consistent with previous reports from Tanzania Demographic and Health Survey, 2015-16 [7] and a previous study in Nigeria [11]. Our result is also in line with a previous report in Ethiopia [8]. A previous report by WHO in 2013 revealed that injectable method was the commonest method used in Eastern and Southern Africa while female sterilization was commonly used worldwide [12]. Reasons for preferring these methods may be explained by their reliability and that the methods are short lived and can be reversed.

In this study women with formal education were more likely to use modern contraceptive methods compared to women without formal education. Similar findings were reported elsewhere [13] [14].

This study shows that desire for more children was negatively associated with the use of modern contraceptives. This finding is consistent with a previous study Tanzania [14]. In the present study men with desire for more children made the women less likely to use modern contraceptive compared with when couples agreed on the same number of children. One possible explanation for this could be attributed to culture that having more children is a sign of prestige. This indicates the need for education on family planning to promote awareness in the community.

Husbands/partners disapproval, low level of education of partners', fear of side effects, poor spousal communication, lack of awareness on family planning, desire for more children were the most reported barriers of using modern contraceptive methods in the present study. Similar findings were reported in a 
study done in Tanzania by Schuler and his colleagues, they found that women whose husbands disapproved were less likely to use modern contraceptive [15]. Previous authors also revealed that having a huge number of children was considered a sign of prestige for men [14] [15]. This was also the case in the present study. Our findings are also consistent with studies done in Nigeria and Ethiopia [8] [10] [11] [16]. This may be explained by existence of a belief that having more children is a sign of prestige. Husbands or partners need to be educated on family planning so that they can support women to use modern contraceptive methods to enhance child spacing to improve maternal and child health.

\section{Strengths and Limitations of the Study}

Most of the findings in our studies are consistent with previous studies. This provides us with confidence for our results. Our study provides important basic information to facilitate planning for strategies to promote modern contraceptives.

Despite the strengths of this study, there some limitations which need to be taken into account while interpreting our results. We were not able to reach the very remote areas as it was very difficult to go from one village to another as the villages were found far away from one to another. Therefore, women who are residing in a remote area may have different utilization of modern contraceptives. If this is true, our study may be affected by selection bias.

\section{Conclusions}

We have found high prevalence of modern contraceptive use among women of reproductive age in rural areas in the study area compared to that of the regional prevalence. Injectable, male condoms and implants were frequently used. Furthermore, age of the participant, level of education, number of living children, employment and spousal communication influenced the use of modern contraceptive, while husband disapproval was reported to be the barrier for use of modern contraceptive for most of the women in the study area. Therefore, district health office and concerned stakeholders should focus on couples to encourage communication and male involvement for family planning.

Education should be provided to all women on the importance of modern contraceptive methods and their side effects. Also, men have to be educated on FP so that they can support their partners. More research on family planning should be done and men should be involved in the study to explore more of their perception on modern contraceptive methods and to find out why there is still high population in district.

\section{Ethics Approval and Consent to Participate}

Ethical clearance was obtained from Kilimanjaro Christian Medical University College Research Ethics Committee. Permission to carry out the study was obtained from Shinyanga region and Kishapu district administrative authorities. 
Written consent was obtained from every participant except for participants aged under 18 years where a written consent was obtained from parents of children as well as assent from the participants themselves. Anonymity was maintained by using codes instead of names to hide the identity. Participation was voluntary has the right to withdraw from the study without giving any reason was explained.

\section{Consent for Publication}

The permission to publish the data was obtained from the study participants after being fully informed about the objectives of the medical birth registry project.

\section{Availability of Data and Material}

The datasets analysed during the current study are not publicly available to protect the participants' anonymity, but are available from the corresponding author on reasonable request.

\section{Conflicts of Interest}

The authors declare that they have no competing interests. All authors read and approved the final manuscript.

\section{Funding}

This work was supported by the KCMC-Duke Medical Education Partnership Initiative-Mentored Research Training Program (MEPI-MTRP). The funding agent has no competing interest in this research.

\section{Authors' Contributions}

VM designed the study, participated in data collection, performed the statistical analysis and participated in the writing of the manuscript. SEM, DJD, NK and BJ contributed in reviewing the manuscript for intellectual content; MJM participated in drafting the manuscript, reviewing and performed the statistical analysis. All authors read and approved the final manuscript.

\section{Acknowledgements}

The authors are indebted to the KCMC-Duke Medical Education Partnership Initiative-Mentored Research Training Program (MEPI-MTRP) for funding this research project. Our sincere gratitude also goes to all supervisors, data collectors, study participants, Shinyanga Regional Officer, Kishapu District Officer and respective village administrations of Kishapu district for their cooperation and support during the study period.

\section{References}

[1] World Health Organization (2015) Health in 2015: From Millennium Development 
Goals to Sustainable Development Goals. http://www.who.int/gho/publications/mdgs-sdgs/en

[2] United Nation Department of Economic and Social Affairs, Population Division (2015) Trends in Contraceptive Use Worldwide 2015. United Nations, Department of Economic and Social Affairs, Population Division (2015). Trends in Contraceptive Use Worldwide 2015 (ST/ESA/SER.A/349).

[3] Kavanaugh, M.L. and Anderson, R.M. (2013) Contraception and Beyond: The Health Benefits of Services Provided at Family Planning Centers. Guttmacher Institute, New York.

[4] Wilcher, R., Petruney, T., Reynolds, H.W., Wilcher, R., Petruney, T., Reynolds, H.W., et al. (2008) From Effectiveness to Impact: Contraception as an HIV Prevention Intervention. Sexually Transmitted Infections, 84, ii54-ii60. https://doi.org/10.1136/sti.2008.030098

[5] Creanga, A.A., Gillespie, D., Karklins, S. and Tsui, A.O. (2011) Low Use of Contraception among Poor Women in Africa: An Equity Issue. Bulletin of the World Health Organization, 89, 258-266. https://doi.org/10.2471/BLT.10.083329

[6] Zimbabwe National Statistics Agency and ICF International (2016) Zimbabwe Demographic and Health Survey 2015: Final Report. Zimbabwe National Statistics Agency (ZIMSTAT) and ICF International, Rockville.

[7] Ministry of Health, Community Development, Gender, Elderly and Children (MoHCDGEC) [Tanzania Mainland], Ministry of Health (MoH) [Zanzibar], National Bureau of Statistics (NBS), Office of the Chief Government Statistician (OCGS), and ICF (2016) Tanzania Demographic and Health Survey and Malaria Indicator Survey (TDHS-MIS) 2015-16. MoHCDGEC, MoH, NBS, OCGS, and ICF, Dar es Salaam and Rockville.

[8] Mohammed, A., Woldeyohannes, D., Feleke, A. and Megabiaw, B. (2014) Determinants of Modern Contraceptive Utilization among Married Women of Reproductive Age Group in North Shoa Zone, Amhara Region, Ethiopia. Reproductive Health, 11, Article No. 13. https://doi.org/10.1186/1742-4755-11-13

[9] National Bureau of Statistics Ministry of Finance Dar es Salaam (2012) Population and Housing Census. Population Distribution by Administrative Areas World Health Organization. Contraception Fact Sheet, 2014. http://who.int/mediacentre/factsheets/fs351/en

[10] Igbodekwe, F.C., Oladimeji, O., Oladimeji, K.E., Adeoye, I.A., Akpa, O.M. and Lawson, L. (2014) Utilisation of Modern Contraceptive among Women of Childbearing Age in Resource Constraint Setting: Evidence from 2008 National Demographic and Health Survey in Nigeria. Journal of Health Sciences, 4, 72-78.

[11] Egede, J.O., Onoh, R.C., Umeora, O.U.J., Iyoke, C.A., Dimejesi, I.B.O. and Lawani, L.O. (2015) Contraceptive Prevalence and Preference in a Cohort of South-East Nigerian Women. Patient Preference and Adherence, 9, 707-714. https://doi.org/10.2147/PPA.S72952

[12] United Nations (2013) World Contraceptive Patterns 2013. United Nations, New York, 11-12.

[13] Asiimwe, J.B., Ndugga, P., Mushomi, J., Patrick, J. and Ntozi, M. (2014) Factors Associated with Modern Contraceptive Use among Young and Older Women in Uganda: A Comparative Analysis. BMC Public Health, 14, 926. https://doi.org/10.1186/1471-2458-14-926

[14] Kidayi, P.L., Msuya, S., Todd, J., Mtuya, C.C., Mtuy, T. and Mahande, M.J. (2015) Determinants of Modern Contraceptive Use among Women of Reproductive Age in 
Tanzania: Evidence from Tanzania Demographic and Health Survey Data. Advances in Sexual Medicine, 5, 43-52. https://doi.org/10.4236/asm.2015.53006

[15] Schuler, S.R., Rottach, E. and Mukiri, P. (2011) Gender Norms and Family Planning Decision-Making in Tanzania: A Qualitative Study. Journal of Public Health in Africa, 2, e25. https://doi.org/10.4081/jphia.2011.e25

[16] Adebowale, A.S. and Morhason-Bello, I. (2015) Survival Analysis of Time to Uptake of Modern Contraceptives among Sexually Active Women of Reproductive Age in Nigeria. BMJ Open, 5, e008371. https://doi.org/10.1136/bmjopen-2015-008371 